\title{
Las primeras imágenes occidentales de los indígenas americanos: entre la tradición medieval y los inicios de la antropología moderna
}

\author{
Sandra SÁENZ-LóPEz PÉREZ \\ Universidad Complutense de Madrid
}

\begin{abstract}
RESUMEN
Desde el primer momento de su llegada a América, los europeos entraron en contacto con los indígenas, a los que no tardaron en retratar gráficamente. Este artículo analiza las representaciones occidentales de las poblaciones nativas americanas desde la primera de ellas, de 1493, hasta mediados del siglo XVI, cuando los viajeros al Nuevo Mundo comenzaron a ser responsables de sus creaciones artísticas, y con ellas testimoniaron sus propias experiencias. En las imágenes realizadas a lo largo de este tiempo se puede apreciar cómo la visión del indio americano, que inicialmente entroncaba con el repertorio iconográfico (y legendario) de la Edad Media, evoluciona hacia una mirada más científica que bien podríamos calificar de antropológica.
\end{abstract}

Palabras clave: Nuevo Mundo; el "otro"; indios del Caribe; tupinambá de Brasil; canibalismo.

\section{The first western images of native americans: between medieval tradition and the beginnings of modern anthropology}

\begin{abstract}
Europeans initiated contact with the American Indians upon arriving in the New World, and they quickly began to portray them. This article analyzes Western images of Native American populations from the first image made in 1493 until the mid-sixteenth century, when travelers to the New World started to become responsible for their artistic creations, which were used as testaments to own experiences. Throughout this period of time the image of the American Indian evolved from an initial dependence on the iconographic (and legendary) repertoire of the Middle Ages towards a more scientific look that we could describe as anthropological.
\end{abstract}

Keywords: New World; The “Other”; Indians of the Caribbean; Tupinambá of Brazil; cannibalism.

Con la llegada de Cristóbal Colón a América el 12 de octubre de $1492^{1}$, se inició el verdadero "descubrimiento del mundo y del hombre", que según el historiador

112 de octubre de 1492 según el calendario juliano, 21 de octubre del calendario gregoriano moderno. 
francés Jules Michelet (1798-1874) caracterizaría la época del Renacimiento ${ }^{2}$. Antes de 1492 Europa ya había llegado a partes de la tierra desconocidas y entrado en contacto con nuevas gentes, muy especialmente a través de la circunnavegación portuguesa de África que consiguió conectar Europa y Asia por mar. No obstante, esas gentes que los europeos conocieron durante las primeras décadas de la llamada "era de los descubrimientos" no resultaron tan sorprendentes como lo fue el encuentro con los indígenas americanos; en el siglo XV, y gracias en gran medida a la literatura geográfica y a los libros de viajes de la Antigüedad y Edad Media, Europa estaba bastante familiarizada con, por ejemplo, el color oscuro de la piel de los africanos, la religión musulmana, e incluso ciertas razas monstruosas, como los amyctyrae, de labios tan grandes que podían con ellos cubrirse el rostro y protegerse del sol ${ }^{3}$, y cuya existencia podría tener su explicación en la costumbre de ciertos pueblos africanos de agrandarse los labios con platos $^{4}$.

La importancia de la llegada al Nuevo Mundo se dejó sentir desde pronto. El cronista de Indias Francisco López de Gómara (1511-1566) decía en la dedicatoria a Carlos V de su Historia general de las Indias (1552), que dicho descubrimiento era "la mayor cosa después de la creacion del mundo, sacando la encarnacion y muerte del que lo crió [sic]"s. Conscientes de la trascendencia de este acontecimiento, muchos de los que allí viajaron trataron de recoger textual y gráficamente sus experiencias, lo que sin duda alguna no resultaba fácil, a juzgar por sus propios comentarios: Gonzalo Fernández de Oviedo y Valdés (1478-1557), otro cronista de Indias, considerado el primer viajero a América que captó en imágenes lo que allí vio, decía en su Historia general y natural de las Indias, al referirse a un árbol, que

"es mas para verle pintado de mano de berruguete u otro excelente pintor como el $o$ aquel Leonardo de vince o andrea mantheña famosos pintores que yo conoci en Italia que no para darle a entender con palabras. E muy mejor que todo esto es para visto que escripto ni pintado"6.

2 "Deux choses... appartiennent à cet âge [i.e. Renaissance] plus qu'à tous ses prédécesseurs: la découverte du monde, la découverte de l'homme", en MICHELET, Jules, Histoire de France, vol. 7, Renaissance, Paris, L. Hachette, 1855, p. ii. El historiador Jacob Burckhardt (1818-1897) contribuyó a la difusión de esta idea al titular la cuarta parte de su Die Cultur der Renaissance in Italien, Basilea, [s.e.], 1860, como "The Discovery of the World and of Man".

3 FRIEDMAN, John Block, The Monstrous Races in Medieval Art and Thought, Cambridge, MA, Harvard University Press, 1981, pp. 10-11.

4 Véase al respecto MASSING, Jean Michel, "The Image of Africa and the Iconography of Lip-Plated Africans in Pierre Desceliers's World Map of 1550", en EARLE, Thomas Foster y LOWE, Kate J.P. (eds.), Black Africans in Renaissance Europe, Cambridge; New York, Cambridge University Press, 2005, pp. 48-69 (reed. en Studies in Imagery, II: The World Discovered, London, Pindar Press, 2007, pp. 49-72).

DE VEDIA, Enrique (ed.), Historiadores primitivos de Indias, 2 vols., Madrid, Imp. y estereotipia de M. Rivadeneyra, 1852-1853, vol. 1, p. 156.

6 GONZALO FERNÁNDEZ DE OVIEDO Y VALDÉS, La historia natural y general de las Indias (Sevilla, 1535), fol. 91v. 
El hallazgo de dibujos originales realizados in situ durante las exploraciones es prácticamente imposible, ya que se consideraban transitorios, y su única finalidad era la de ser trasladados a una obra definitiva y más acabada; una vez hecho esto, los dibujos originales se destruirían ${ }^{7}$. Bien avanzado el siglo XVI sí tenemos constancia de la participación de artistas en las exploraciones para registrar gráficamente aquello que se descubría. Por ejemplo, conservamos con fecha de 1582 unas Instructions for a voyage of discovery dirigidas a Thomas Bavin para que documentara de forma completa la topografía, recursos naturales y la vida indígena de la costa oriental de Norteamérica ${ }^{8}$; en ellas se le especifica que

"also drawe to life all strange birdes beastes fishes plantes hearbes Trees and fruictes and bring home of eache sorte as nere as yoy may. Also drawe the figures and shapes of men and women in their apparell as also of their manner of wepons in every place as you shall finde them differing"".

Uno de los artistas de ese momento que mejor supo traducir en imágenes ese Nuevo Mundo tan diferente del Viejo, fue el inglés John White (ca. 1540-ca. 1593), quien trabajó en la colonia establecida en Roanoke Island, próxima a la moderna Carolina del Norte (1584-1590), y realizó retratos de sus habitantes y de sus costumbres ${ }^{10}$.

Pero en las primeras exploraciones al Nuevo Mundo no se reclutaron artistas, y las imágenes que ilustraron esos viajes fueron realizadas en Europa a partir de las descripciones textuales de los exploradores. Además, generalmente estos últimos no intervenían en el proceso creativo, por lo que el resultado era fruto de las interpretaciones de artistas occidentales que nunca habían estado en América, y que solamente podían recurrir a un lenguaje gráfico anclado en la Edad Media ${ }^{11}$. Como

7 HULTON, Paul H. y QUINN, David B., "The Role of the Artist in the Voyage of Discovery", en The American Drawings of John White (1577-1590), 2 vols., London, The Trustees of the British Museum, 1964, vol 1, p. 31.

8 British Library, London (Add. Ms. 38823, fols. 1r-8r). En relación con este documento, véase "Instructions for a Voyage of Reconnaissance to North America in 1582 or 1583", en QUINN, David B. (ed.), New American World: A Documentary History of North America to 1612, 5 vols., Nueva York, Arno Press, 1979, vol. 3, pp. 239-245.

9 British Library, London (Add. Ms. 38823, fol. 6r), en Ibid, p. 244.

10 Para la obra de John White, véase BINYON, Laurence, "The Drawings of John White, Governor of Raleigh's Virginia Colony”, en The Walpole Society, vol. 13, 1924-1925, pp. 19-24 (+ imágenes); HULTON, Paul H. y QUINN, David B. (1964), op. cit.; HULTON, Paul H., America 1585: The Complete Drawings of John White, Chapel Hill, University of North Carolina Press-London, British Museum Publications, 1984; SLOAN, Kim (ed.), A New World. England's First View of America, Chapel Hill, University of North Carolina Press, 2007; así como la colección de artículos recogidos en Idem (ed.), European Visions: American Voices, London, British Museum, 2009.

11 John H. Elliott afirma al respecto que "his European background and training were likely to determine the nature of his vision; and the techniques and the colour range with which he had familiarized himself at home were not necessarily adequate to represent the new and often exotic scenes which he now set out to record", en ELLIOTT, John H., The Old World and the New, 1492-1650, Cambridge, Cambridge University Press, 1970, pp. 22-23. 
consecuencia de ello, podemos afirmar que a través del vocabulario lexicográfico que los occidentales utilizaron al referirse textual y gráficamente al Nuevo Mundo, América y su población nativa fueron inventadas; el Viejo Mundo impuso sus valores, percepciones y prejuicios sobre las cosas —y las gentes - del Nuevo ${ }^{12}$.

Las primeras representaciones de los indígenas americanos están basadas en las descripciones que aportaron Cristóbal Colón y Américo Vespucio. Y tanto en las imágenes que ilustran las narraciones colombinas como las vespucianas encontramos claros referentes iconográficos de Occidente, y así podemos apreciar, por ejemplo, en la xilografía titulada "Insula Hyspana" perteneciente a la carta colombina De insulis inventis. Espistola Cristoferi Colom, impresa en Basilea en 1493-1494 ${ }^{13}$. Dicha imagen es especialmente conocida por ilustrar por vez primera a los indígenas americanos, posiblemente en el momento en el que la expedición colombina llega a la Española. En la parte inferior encontramos una embarcación con las banderas de León y Aragón; se trata de una galera típica del mar Mediterráneo, inútil para las expediciones transatlánticas —como es bien conocido, el primer viaje colombino alcanzó América a bordo de una nao (la Santa María) y dos carabelas (la Pinta y la Niña)-. La representación de una galera de remos en los mares del Nuevo Mundo revela, pues, el desconocimiento del artista, quien, como ha demostrado Gloria Deák, recurrió a la imagen especular de la embarcación ilustrada por Reuwich en la vista de Rodas, en la Peregrinatio in Terram Sanctam de Bernhard von Breydenbach (Maguncia, 1486) ${ }^{14}$.

En las publicaciones de los textos de Américo Vespucio, las imágenes del Nuevo Mundo también tienden a occidentalizarse. Dentro de estas, la primera representación de los nativos americanos aparece en la edición alemana del Mundus Novus ${ }^{15}$ titulada Van den nygen Insulen und landen so ytzundt kortliken befunden sindt dorch den Konigk van Portugal (Magdeburgo, Jacob Winter, 1506), donde se ilustra a una pareja de indígenas cubriéndose el sexo con vergüenza ${ }^{16}$, cuando sin embargo, como insistió en varias ocasiones el propio Vespucio, los nativos americanos mostraban su cuerpo desnudo con gran naturalidad: "todos de uno y otro

12 Para la idea de la invención de América, véase O'GORMAN, Edmundo, The Invention of America: An Inquiry into the Historical Nature of the New World and the Meaning of its History, Bloomington, University of Indiana Press, 1961.

13 Para una reproducción facsimilar de esta carta, véase FIRPO, Luigi (ed.), Prime relazioni di navigatori italiani sulla scoperta dell'America. Colombo, Vespucci, Verazzano, Torino, Unione Tipografico; Editrice torinese, (1965), pp. 13-32.

14 DEÁK, Gloria, “The New World Depicted: Renaissance Woodcuts of 1493”, en The Print Collector's Newsletter, vol. 23, nº 4, 1992, p. 123.

15 El Mundus Novus de Américo Vespucio fue sin duda uno de los textos sobre los nuevos descubrimientos que más popularidad alcanzó; derivada de la primera carta de Vespucio a Lorenzo di Pierfrancesco de Médici, fue publicada en París en 1503 y posteriormente en Roma, Venecia y Augsburg en 1504. Fue traducida a cinco idiomas y editada casi treinta veces antes de 1515.

16 Para una ilustración de esta xilografía, véase COLIN, Susi, Das Bild des Indianers im 16. Jahrhundert, Idstein, Schulz-Kirchner, 1988, p. 407, fig. 20. 
sexo van desnudos, no se cubren ninguna parte del cuerpo, y así como han salido del vientre de la madre así hasta la muerte van" ${ }^{17}$. Indudablemente, el punto de inspiración de la representación de esta pareja americana fue la imagen tradicional de Adán y Eva, una vez cometido el pecado original ${ }^{18}$.

Las imágenes occidentales de los indígenas americanos realizadas desde el regreso de Cristóbal Colón de su primer viaje en 1493, y a lo largo de las siguientes décadas, e incluso centurias, son muy numerosas. No es este el lugar para intentar abordar el análisis de todas ellas, y además, este campo de estudio ya ha dado como fruto trabajos de gran interés ${ }^{19}$. El propósito de este artículo es incidir en la evolución iconográfica de los retratos occidentales de los indígenas americanos hasta mediados del siglo XVI, cuando el número de obras de artistas que habían viajado a América comienza a incrementarse. Dicha evolución muestra el paso de un inicio aún marcado por la tradición medieval a una aproximación más científica y moderna, que bien podríamos definir como antropológica y etnográfica. Nos centraremos especialmente en los retratos de los indios del Caribe - que conociera Colón por primera vez-y de los indios tupinambá, con los que entrara en contacto Pedro Álvares Cabral en su inesperada llegada a Brasil en 1500, y sobre todo, poco después, Américo Vespucio. Aunque dentro del marco cronológico de este trabajo existen imágenes occidentales de nativos americanos pertenecientes a otros grupos culturales y ámbitos geográficos, por ejemplo, los aztecas de $\mathrm{México}^{20}$, fueron los del Caribe y Brasil los que inicialmente acapararon el mayor interés artístico. Las imágenes que los retratan inciden en sus características físicas y en sus costumbres,

17 AMÉRICO VESPUCIO, Cartas, Madrid, Anjana Ediciones, 1983, p. 47.

18 COLIN, Susi (1988), op. cit., pp. 31-32.

19 Dentro de la amplia bibliografía referente a las primeras imágenes occidentales de los indígenas americanos, pueden destacarse: STURTEVANT, William C. "First Visual Images of Native America", en CHIAPPELLI, Fredi, ALLEN, Michael J.B. y BENSON, Robert L. (eds.), First Images of America: the Impact of the New World on the Old, 2 vols., Berkeley, University of California Press, 1976, vol. 1, pp. 417-454; HONOUR, Hugh, The European Vision of America: A Special Exhibition to Honor the Bicentennial of the United States, Organized by the Cleveland Museum of Art..., Cleveland, Cleveland Museum of Art, 1975; ALEGRÍA, Ricardo E., Las primeras representaciones gráficas del Indio Americano, 1493-1523, San Juan, Puerto Rico, Centro de Estudios Avanzados de Puerto Rico y el Caribe, 1978; COLIN, Susi (1988), op. cit.; MASSING, Jean Michel, "Early European Images of America: The Ethnographic Approach", en LEVENSON, J.A. (ed.), Circa 1492. Art in the Age of Exploration, New Haven, Yale University Press, 1991, pp. 514-520 (reimpreso en MASSING, Jean Michel, Studies in Imagery, vol. II: The World Discovered, 2 vols., Londres, The Pindar Press, 2007, pp. 94-113); AMODIO, Emanuelle, "El otro americano. Construcción y difusión de la iconografía del indio americano en Europa en el primer siglo de la conquista", en Montalbán, vol. 24, 1992, pp. 33-84; y SEBASTIÁN, Santiago, Iconografía del indio americano siglos XVI y XVII, Madrid, Ediciones Tuero, 1992.

20 Son interesantes, por ejemplo, las representaciones de los indios aztecas traídos por Hernán Cortés a la corte de Carlos V, e ilustradas del natural en Toledo o Barcelona por Christoph Weiditz, un artista de Augsburgo; véase al respecto CLINE, Howard F. "Hernando Cortés and the Aztec Indians in Spain", Quarterly Journal of the Library of Congress, vol. 26, $\mathrm{n}^{\circ}$ 2, 1969, pp. 70-90; y BRIESEMEISTER, Dietrich, "Sobre indios, moriscos y cristianos 'a su manera': Testimonios pictóricos en el 'Trachtenbuch' de Christoph Weiditz”, en Jahrbuch für Geschichte Lateinamerikas (= Anuario de Historia de América Latina), vol. 43, 2006, pp. 1-24. 
así como en los objetos que constituían su cultura material; los artistas occidentales pusieron de relieve aquello que les resultaba más llamativo, por no ser identificado como "cristiano" o "civilizado". Y de todo ello, lo que indudablemente cautivó más la atención, e incluso podríamos decir la imaginación del hombre occidental, fue la práctica antropofágica, es decir, el comer carne humana ${ }^{21}$, que en América recibió el nombre de canibalismo.

Según se desprende de su Diario, el 23 de noviembre de 1492, Cristóbal Colón escuchó por primera vez el término "caníbal" de boca de unos indios taínos que iban con él, quienes se refirieron a "...gente que tenía un ojo en la frente, y otros que se llamavan caníbales, a quienes mostraban tener gran miedo... porque los comían..."22. Además de los tradicionales cíclopes o monoculi (esa "gente que tenía un ojo en la frente" descritos por Colón), días antes, el 4 de noviembre, mencionaba en su Diario la existencia de otros monstruos que por sus costumbres culinarias bien podían identificarse con los temidos caníbales: de la descripción dada por unos indígenas, Colón "entendió también que lexos de allí avía hombres de un ojo y otros con hoçicos de perros que comían los hombres, y que en tomando uno lo degollaban y le bevían la sangre y le cortavan su natura"23. Los caribes caníbales adquirían así la forma de los tradicionales cinocéfalos. Y no es de extrañar que esto ocurriera, pues recordemos que Cristóbal Colón creía estar en Asia, y en esa tierra, viajeros medievales como Marco Polo (1254-1324) o Jean de Mandeville (m. 1372), que nutrían la imaginación colombina, habían localizado seres monstruosos tales como cíclopes o monoculi y cinocéfalos. Más aún, Cristóbal Colón pensaba que había llegado a las islas orientales, y aquí, con anterioridad, se habían localizado pueblos de semejantes características físicas y costumbres alimentarias. Marco Polo había dicho en su Il Milione que los habitantes de las islas Andamán

21 Algunos investigadores - entre ellos William Arens a la cabeza - han tratado de desmentir, o han puesto en duda, la existencia de esta práctica; véase ARENS, William, The Man-Eating Myth: Anthropology \& Anthropophagy, New York, Oxford University Press, 1980; y FRANK, Erwin, "'Sie Fressen Menschen, wie ihr scheußliches Aussehen beweist...' Kritische Überlegungen zu Zeugen und Quellen der Menschenfresserei”, en DUERR, Hans Peter (ed.), Authentizität und Betrug in der Ethnologie, Frankfurt, Suhrkamp, 1987, pp. 199-224. Sin embargo, son muy numerosos los antropólogos, arqueólogos e historiadores que han podido documentar la existencia de testimonios fiables y restos materiales que avalan la práctica de la antropofagia en América; véase, por ejemplo, ABLER, Thomas S., "Iroquois Cabbibalism: Fact Not Fiction", en Ethnohistory, vol. 27, no 4, 1980, pp. 309-316; FORSYTH, Donald W., "Three Cheers for Hans Staden: The Case for Brazilian Cannibalism", en Ethnohistory, vol. 32, n 1, 1985, pp. 17-36; MARLAR, Richard A. et al., "Biochemical Evidence of Cannibalism at a Prehistoric Puebloan Site in Southwestern Colorado", en Nature, vol. 407, 2000, pp. 74-78; LUNA CALDERÓN, Fernando, "ADN mitocondrial taino en la República Dominicana", en KACIKE, Revista de la historia y antropología de los indígenas del Caribe, 2002, http://www.kacike.org/CalderonEspanol.html; STONEKING, Mark, "Widespread Prehistoric Human Cannibalism: Easier to Swallow?”, en Trends in Ecology \& Evolution, vol. 18, n 10, 2003, pp. 489-490; VENTO CANOSA, Ercilio, "Antropofagia en aborígenes de Cuba [Anthropography in Cuban Aborigines]", en Revista médica electrón, vol. 27, n 3, 2005, pp. 36-45.

22 VARELA, Consuelo (ed.), Cristóbal Colón. Textos y documentos completos, Madrid, Alianza, 1984, p. 62 .

${ }^{23}$ Ibid., p. 51. 
(golfo de Bengala) “...no hacen ascos a carne alguna, pues comen carne humana. Sus hombres son muy monstruosos, pues hay unos que tienen cabeza de perro y ojos parecidos a los caninos" ${ }^{24}$. Algunos manuscritos iluminados de su obra, por ejemplo, el del Duque de Berry (ca. 1410-1412) ${ }^{25}$, los presentan según dicha descripción, con cabeza canina.

La identificación de esta población oriental como caníbales cinocéfalos se dejó sentir dentro del terreno de la cartografía. En la Tabla moderna de las Indias Orientales de las ediciones de la Geografía de Ptolomeo de Lorenz Fries (1522, 1525, 1535 y 1541), encontramos en Andamán (escrito como ANGAMA) la imagen de un personaje masculino descuartizando con un hacha a una víctima, que yace sobre una mesa de carnicero; algunas partes de su cuerpo o restos de otras víctimas cuelgan de las ramas de los árboles circundantes; dos personajes femeninos colaboran en la carnicería, una sosteniendo el brazo izquierdo de la víctima, que posiblemente va a ser amputado, y la otra llevando en una bandeja redonda una mano y otros restos ya cortados ${ }^{26}$. Aunque los habitantes de Andamán carecen de la cabeza canina que describía Marco Polo, el texto sobre la imagen dice de ellos que: ...habentes eciam deformata capita quasi canina (i.e. "...tienen deforme la cabeza casi canina" ${ }^{27}$. Asimismo, bajo la representación se especifica que son antropófagos: Hic sunt antropophagi. La idea de los cinocéfalos caníbales de las islas orientales perduró dentro de la cartografía ${ }^{28}$, como encontramos por ejemplo en la isla de Java del mappamundi de 1550 del francés Pierre Desceliers ${ }^{29}$, donde reaparece la mesa de carnicero, el hacha y la carne secándose en ramas. La principal diferencia respecto de la imagen anterior es que los habitantes de Andamán tienen cabezas de perro; sus víctimas son también cinocéfalos, por lo que deben ser identificados como habitantes de la propia isla, y no como extranjeros ${ }^{30}$.

24 GIL, Juan (ed.), El libro de Marco Polo anotado por Cristóbal Colón, Madrid, Alianza, 1987, p. 142.

25 Bibliothèque nationale de France, París (Ms. français 2810, fol. 76v). La imagen está digitalizada online en "Mandragore", la base de manuscritos iluminados de la BnF: http://mandragore.bnf.fr/jsp/rechercheExperte.jsp.

${ }^{26}$ La edición de 1525 está digitalizada online en la "Digital Collections" de la Sächsische Landesbibliothek -Staats- und Universitätsbibliothek de Dresden: http://www.slub-dresden.de/en/sammlungen/digitalcollections/collections/.

27 Una leyenda semejante aparecía con anterioridad en el mappamundi de Martin Waldseemüller (1507), conservado en la Library of Congress, Washington, D.C. (G3200 1507.W3 Vault): Isti sunt ydolatre bestialiter uiuunt omnium aromatum copia ibi est habent homines deformata capita quasi canina.

28 Por ejemplo, en la Carta marina de Lorenz Fries de 1525 (reimpresa en 1527 y 1530).

29 British Library, Londres (Add. Ms. 24065). Para una reproducción facsimilar en blanco y negro de este mapa, véase Bibliotheca Lindesiana. Collations and Notes. $N^{\circ} 4$. Autotype facsimiles of three mappemondes, [s.1.], [privately printed], 1898, mapa 3, The mappemonde by Desceliers of $1550 \ldots$

30 De hecho, el texto explicativo de esta representación se refiere a ellos como gente nativa de la isla y dice de ellos que son antropófagos, que tiene la cabeza, dientes y ojos casi como de perro, y que compran los cuerpos de las ancianas y de los niños, y que cuando mueren, se los comen diciendo que eso es más honesto que dejar que se los coman los gusanos; dicho texto está parcialmente transcrito en MASSING, Jean Michel, "La mappemonde de Pierre Desceliers de 1550", en OURSEL, Hervé y FRITSCH, Julia (eds.), Henri II et les 
Aunque en la carta que Cristóbal Colón remitió a Luis de Santángel en 1493 reconoció no haber encontrado monstruos, sino gente de gran hermosura ("En estas islas fasta aquí no he hallado ombres monstrudos, como muchos pensavan, más antes es toda gente de muy lindo acatamiento" ${ }^{31}$ ), la imagen de los caribes de las Antillas que caló con más peso en Europa fue la de seres monstruosos, tanto por sus características físicas, es decir, por tener cabeza de perro, como por sus horrendos actos, el comer carne humana. Así se pone de relieve especialmente en una imagen del Uslegung der carta marina (Estrasburgo, Johannes Grieninger, 1525), un librito explicativo que acompañaba la Carta marina de Lorenz Fries, en el que se ilustra el descubrimiento de Colón mediante la representación de cinocéfalos mutilando un cuerpo humano, mientras que algunos restos desmembrados del mismo se secan al sol, y otro cinocéfalo, a la derecha, disfruta mordiendo un brazo; un extraño animal $^{32}$, conducido por otro cinocéfalo, porta una nueva víctima atada de pies y manos (fig. 1). En las copias coloreadas de esta xilografía se puede apreciar que las víctimas humanas son de piel oscura, es decir, no son de origen europeo, sino muy posiblemente antillano, e incluso podríamos sugerir que se tratara de los propios taínos; de hecho, Cristóbal Colón dijo de ellos en su Diario que "son de la color de los canarios, ni negros ni blancos" $" 33$.

En todas estas representaciones de los cinocéfalos caníbales, tanto de las islas de las Indias Orientales como de las Occidentales, el lenguaje gráfico utilizado carece de valor etnográfico, y hunde sus raíces en el arte occidental medieval. Los artistas que en el siglo XVI tuvieron que representar los actos caníbales de tierras lejanas recurrieron para ello a imágenes preexistentes que les resultaban familiares: los martirios de los muchos santos cuyos cuerpos fueron desmembrados ${ }^{34}$, o el de Nabucodonosor, por su hijo, el rey Evilmerodach, como se ilustra en el Speculum humanae salvationis; la Salomé cargando con la cabeza del Bautista, por ejemplo para la figura femenina con la bandeja de restos humanos de Lorenz Fries; o escenas de carnicerías, como las de los manuscritos iluminados del Tacuinum Sanitatis (un manual médico medieval), en las que encontramos las mismas mesas de carnicero, la misma idea de secar o curar la carne, e incluso el mismo tipo de instrumental de corte. En relación con estas hachas, es significativo destacar que aquellas con

arts: actes du colloque international, École du Louvre et Musée national de la Renaissance-Écouen, 25, 26 et 27 septembre 1997, Paris, École du Louvre, 2003, p. 238.

31 VARELA, Consuelo (1984), op. cit., p. 144.

32 Según Helga von Kügelgen, este animal pudo verlo en la edición de Jean de Mandeville de Augsburg, Anton Sorg, 1481, fol. 88v, en KÜGELGEN, Helga von, "El indio: ¿bárbaro y/o buen salvaje?”, en La imagen del indio en la Europa moderna, Sevilla, Consejo Superior de Investigaciones Científicas; Escuela de Estudios Hispano-Americanos de Sevilla, 1990, p. 13, n. 42. La imagen de Mandeville está reproduccida en SCHRAMM, Albert, Der Bilderschmuck der Frühdrucke, vol. IV, Die Drucke von Anton Sorg in Augsburg, Leipzig, K. W. Hiersemann, 1921, lám. 99 (nº. 692).

33 VARELA, Consuelo (1984), op. cit., p. 31.

34 Véase, por ejemplo, CHICANGANA-BAYONA, Yobenj Aucardo (2009), op. cit., pp. 7-8. 


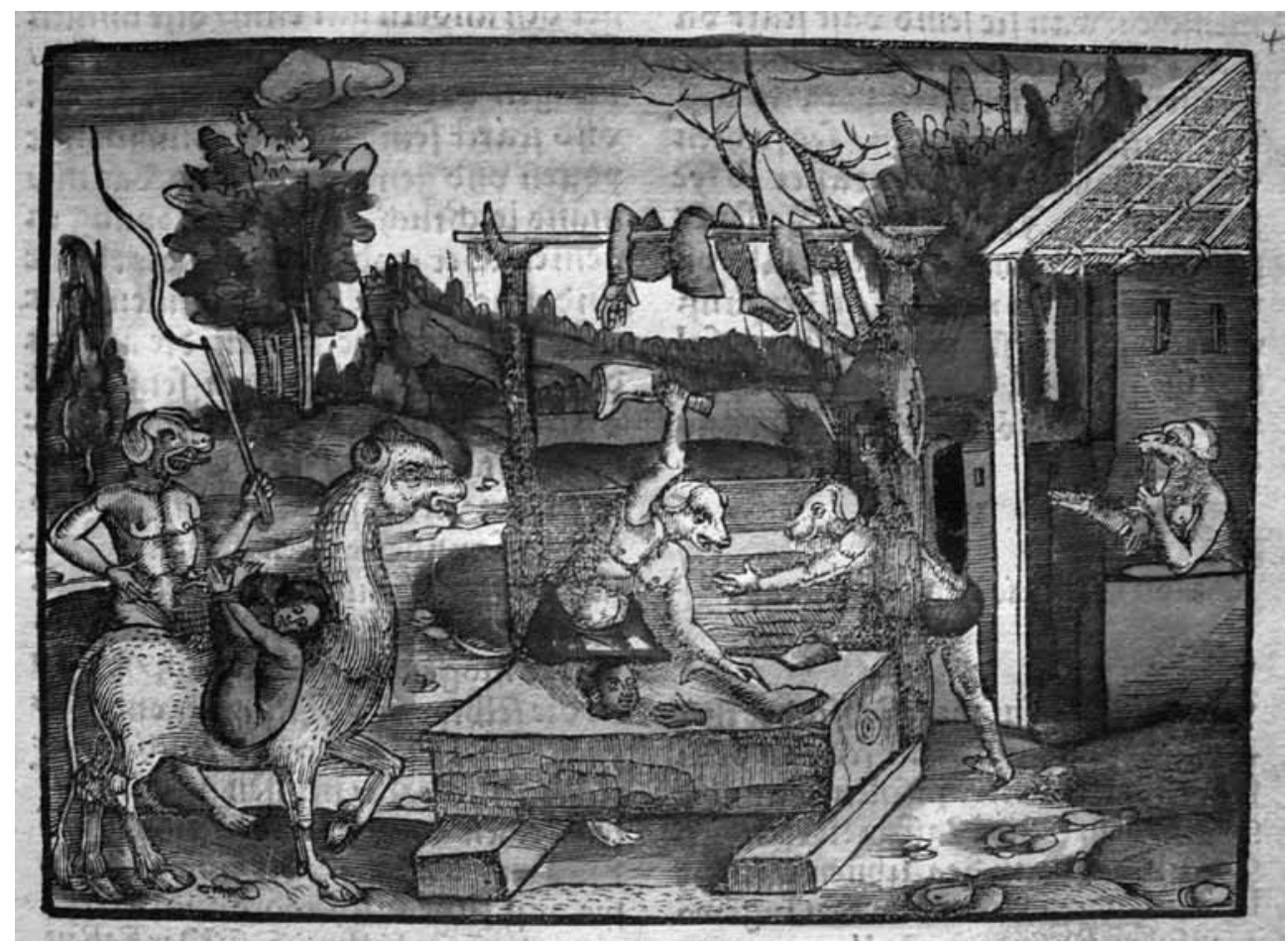

Fig. 1. Lorenz Fries, Uslegung der Carta Marina (Estrasburgo, Johannes Grieninger, 1525).

las que se representa a los caribes caníbales parecen de hierro, cuando sin embargo este metal manufacturado no fue introducido en América hasta la llegada de los europeos; las hachas occidentalizadas difieren pues enormemente de las indígenas de piedra, documentadas por Gonzalo Fernández de Oviedo y Valdés en su Historia natural y general de las Indias (Sevilla, 1535, fol. 61r).

Si a partir de Cristóbal Colón se difundió por Europa la idea de los caribes caníbales de las Antillas, de forma semejante ocurrió con Américo Vespucio y los indios tupinambá de Brasil. Dentro de sus varias menciones al canibalismo americano, la más detallada está recogida en su carta a Piero Soderini, titulada Lettera delle isole novamente ritrovate, escrita en Lisboa en 1504 y publicada en Florencia entre 1504 y 1506. Según esta carta, Vespucio fue testigo de cómo uno de sus compañeros recibió un golpe de muerte, y posteriormente fue asado y comido. Este hecho aparece ilustrado en la edición alemana Disz büchlin saget wie die zwē... herrē ... Fernandus. K. zü Castilien... (Estrasburgo, J. Gruniger, 1509), una de las xilografías ${ }^{35}$ se ajusta al texto fielmente al recoger el momento en que el marinero

35 Esta xilografía está reproducida en ALEGRÍA, Ricardo E. (1978), op. cit., fig. 14. 
“...se fue hacia las mujeres, y cuando llegó junto a ellas le hicieron un gran cerco alrededor, y tocándolo y mirándolo, se maravillaban. Y estando en esto vimos venir una mujer del monte que traía un gran palo en la mano, y cuando llegó donde estaba nuestro cristiano, se le acercó por detrás $y$, alzando el garrote, le dio tan gran golpe que lo tendió muerto en tierra.... ${ }^{36}$.

Aunque el final de esta historia no está ilustrado, otra xilografía ${ }^{37}$ que precede a la anterior, muestra al fondo a una pareja descuartizando un cuerpo - muy semejante al desafortunado destino que experimentó el marinero de la expedición de Vespucio-. Según continúa la narración, en el monte

“...estaban las mujeres despedazando al cristiano, y en un gran fuego que habían hecho, lo estaban asando a nuestra vista, mostrándonos muchos pedazos y comiéndoselos. Los hombres nos hacían señas con sus gestos, de cómo habían muerto a los otros dos cristianos y se los habían comido"38.

También importante para la concepción del canibalismo en Brasil es otra imagen impresa hacia 1505, bajo la cual figura un fragmento textual derivado de la traducción alemana de La Lettera de Vespucio ${ }^{39}$. Dicho texto dice que los indios "se comen entre sí hasta a los mismos asesinados, y cuelgan esa misma carne al humo" ${ }^{40}$, y siguiendo la descripción vemos al fondo miembros humanos (una cabeza, un brazo y una pierna) que cuelgan de una viga sobre un fuego. A la izquierda encontramos a tres personajes alrededor de una superficie en la que quizá se descuartizó a la víctima, y uno de ellos está mordiendo un brazo.

Otro aspecto de gran interés por lo que respecta a esta imagen es que los indígenas están ataviados con ornamentos de plumas. Curiosamente, este es el único detalle que no sigue el relato vespuciano ${ }^{41}$. Tal como afirma Hugh Honour, la principal diferencia existente entre los indígenas del Nuevo Mundo y las restantes razas humanas radicaba en que los primeros iban prácticamente desnudos, tan solo adornados con plumas de ave ${ }^{42}$. Según el texto de la xilografía, "las cabezas, cuellos, brazos, genitales y pies de las mujeres y de los hombres están un poquito cubiertos de plumas"43. Los adornos plumarios de la imagen parecen muy realistas, en concreto los collares, tobilleras y brazaletes, y especialmente el Enduape típico tupinambá. El alemán Hans Staden —a quien mencionaremos nuevamente más adelante-

36 AMÉRICO VESPUCIO (1983), op. cit., p. 85.

${ }_{37}$ Esta xilografía está reproducida en ALEGRÍA, Ricardo E. (1978), op. cit., fig. 15.

38 AMÉRICO VESPUCIO (1983), op. cit., p. 86.

${ }^{39}$ Para esta xilografía, véase WINSOR, Justin (ed.), Narrative and Critical History of America, 8 vols., Boston, Houghton Mifflin Co., 1886, vol. 2, p. 19; EAMES, W. "Description of a Wood Engraving Illustrating the South American Indians 1505", en Bulletin of the New York Public Library, vol. 26, 1922, pp. 755-760; y SCHULLER, Rudolf, "The Oldest Known Illustration of the South American Indians", en Journal de la société des Americanistes de Paris, vol. 16, 1924, pp. 111-118.

${ }^{40}$ KÜGELGEN, Helga von (1990), op. cit., p. 474.

${ }^{41}$ ALEGRÍA, Ricardo E. (1978), op. cit., p. 80.

42 HONOUR, Hugh (1975), op. cit., p. 4.

${ }^{43}$ KÜGELGEN, Helga von (1990), op. cit., p. 474. 
ilustró y describió el Enduape en el libro II, cap. 16 de su Warhaftige Historia und beschreibung eyner landtschafft der Wilnen Nacketen Grimmigen Menschfresser Leuthen in der Newenwelt America (Verdadera historia y descripción de un país de salvajes desnudos, feroces y caníbales, situado en el Nuevo Mundo, América) publicada en 1557 en Marburgo, como un "ornamento realizado con plumas de avestruz, que es una cosa grande y redonda hecha de plumas. Lo atan a sus nalgas cuando van a hacer la guerra contra sus enemigos o cuando tienen una celebración" ${ }^{44}$.

Por lo que respecta a la falda de plumas, muchos investigadores han planteado que fuera una invención europea, ya que no tiene paralelo dentro de la vestimenta indígena brasileña ${ }^{45}$. Quizá a los artistas occidentales les resultaba difícil imaginar a gente desnuda, pero ornamentada con plumas exuberantes, e inventaron esta forma de falda ${ }^{46}$. Otra hipótesis interesante al respecto es que la falda de plumas derivara de una mala interpretación otro objeto etnográfico llevado a Europa y sacado fuera de contexto, como pudiera ser un tocado o una capa de plumas ${ }^{47}$, como los que visten los indios tupinambá ilustrados por António de Holanda en el Atlas Miller (ca. 1519) de Lopo Homem, Pedro Reinel y Jorge Reinel ${ }^{48}$. La clave de esta equivocación parece darla los dibujos de supuestos guerreros aztecas atribuidos a Hans Burgkmair (ca. 1520) ${ }^{49}$, que visten faldas de plumas que no les cubren completamente (como si hubieran sido diseñadas para ceñirse a algo más estrecho, como el cuello), y que dejan al descubierto parte de las caderas ${ }^{50}$.

44 Traducción al español de la autora a partir de la inglesa de WHITEHEAD, Neil L. y HARBSMEIER, Michael (eds. y trads.), Hans Staden's True History. An Account of Cannibal Captivity in Brazil, Durham, N.C., Duke University Press, 2008, p. 120.

${ }_{45}$ Para los adornos plumarios de las tribus de Brasil, véase MÉTRAUX, Alfred, La civilisation matérielle des tribus Tupi-Guarani, Paris, Librairie Orientaliste Paul Geuthner, 1928, pp, 128-161; y RIBEIRO, Berta C., "Bases para uma classificação dos adornos plumários dos índios do Brasil", en Arquivos do Museu Nacional, vol. 43, 1957, pp. 59-119.

46 STURTEVANT, William C. (1976), op. cit., p. 420.

${ }^{47}$ HONOUR, Hugh, "Science and Exoticism: The European Artist and the Non-European World before Johan Maurits", en BOOGAART, Ernst van den (ed.), Johan Maurits van Nassau-Siegen 1604-1679: A Humanist Prince in Europe and Brazil, The Hague, Johan Maurits van Nassau Stichting, 1979, p. 277; y MASON, Peter, Infelicities: Representations of the Exotic, Baltimore, Johns Hopkins University Press, 1998, p. 17.

${ }^{48}$ Bibliothèque nationale de France, París (Rés. Ge DD 683 y Rés. Ge AA 640). Para la atribución de las ilustraciones de este mapa al artista flamenco António de Holanda, véase MARQUES, Alfredo Pinheiro, A Problem Solved: Art in Portuguese Cartography, Chicago, Newberry Library, 1993; e idem, "The Outstanding Artistic Value of the Atlas Miller, a Masterpiece by Lopo Homem, Pedro Reinel, Jorge Reinel and António de Holanda", en MOLEIRO, Manuel (ed.), Atlas Miller, Barcelona, M. Moleiro Editor, 2006, pp. 137-216, esp. 181-208. Para la autoría del mapa, véase CORTESÃO, Armando y MOTA, Avelino Teixeira da, Portugaliae monumenta cartographica, 5 vols., Lisboa, Imprensa Nacional-Casa da Moneda, 1987, vol. 1, pp. 59-61.

49 British Museum, Londres, Prints \& Drawings (SL,5218.128 y SL,5218.129). Esto dibujos está digitalizados en la "Collection Database" del British Museum http://www.britishmuseum.org/research/search_the_ collection_database.aspx.

${ }^{50}$ Más recientemente, William C. Sturtevant planteo que la falda de plumas fuera utilizada por los indios de Brasil en ocasiones especiales, tales como en rituales de danza, ya que con ella aparecen vestidos en mapas europeos del siglo XVI, como el atlas de Jean Rotz de 1542 (al que se hará referencia más adelante), en el 
La primera representación cartográfica de los indios tupinambá aparece en el mapa anónimo portugués llamado Kunstmann $\mathrm{II}^{51}$, y es sin duda interesante señalar al respecto que desde los indicios, los cartógrafos occidentales pusieron de relieve sus prácticas antropofágicas (fig. 2). La representación del canibalismo en Kunstmann II responde a otro modelo iconográfico distinto de los vistos hasta ahora: un indígena arrodillado en el suelo da vueltas sobre el fuego al que será su alimento, un hombre ensartado en un palo. Debido al color claro de la piel de la víctima se ha sugerido que esta fuera de origen europeo, y que consecuentemente la escena pudiera estar inspirada en la muerte del marinero narrada en La Lettera de Vespucio ${ }^{52}$, mencionada anteriormente. De ser así, la fecha del mapa sería posterior a la publicación de la carta de Vespucio, es decir, post quem 1504-1506. Por lo que respecta a la forma de preparar el asado, es interesante señalar que el cartógrafo se distanció de la realidad americana, que muy posiblemente desconocía, y recurrió nuevamente a una imagen más familiar, procedente de la forma cotidiana de asar la carne en Europa, o de representaciones occidentales similares. Entre estas últimas podemos destacar, por ejemplo, la presente en la Chronica majora de Matthew Paris, realizada en el monasterio de St. Albans hacia 1240-1253 $33^{53}$, donde los tártaros o mongoles son acusados de canibalismo: un hombre está siendo cocinado sobre un fuego de forma semejante al mapa de Kunstmann II, otro está siendo decapitado con un hacha, mientras que restos desmembrados de otras víctimas se acumulan por el suelo o son mordidos con voracidad, y otra víctima atada a un árbol espera un final semejante al de sus compañeros ${ }^{54}$.

La representación de víctimas empaladas sobre un fuego para ser asadas por indígenas brasileños — como en Kunstmann II - o por mongoles — como en la Chronica majora - alcanzó su máximo desarrollo en la iconografía medieval del infierno ${ }^{55}$. Entre los tormentos infernales, pecadores, en muchos casos acusados

que los restantes elementos ilustrados resultan etnográficamente bastante correctos. Véase STURTEVANT, William C., "La Tupinambisation des Indiens d'Amérique du Nord", en THÉREN, G. (ed.), Les figures de l'Indien, Ontario, Université du Québec à Montreal, 1988, p. 294; idem, "The Ethnographical Illustrations", en WALLIS, Helen (ed.), The Maps and Text of the Boke of Idrography Presented by Jean Rotz to Henry VIII, Now in the British Library, Oxford, V. Eccles, 1981, p. 71; idem, "Indian America: First Visual Impressions in Europe", en BEDINI, S.A. (ed.), The Christopher Colombus Encyclopedia, New York, Simon \& Schuster, 1991, vol. 1, p. 339; e idem, "The Sources for European Imagery of Native Americans", en DOGGETT, Rachel, HULVEY, Monique y AINSWORTH, Julie (eds.), New World of Wonders. European Images of America (1492-1700), Washington, DC., The Folger Shakespeare Library, 1992, p. 28.

${ }_{51}$ Bayerische Staatsbibliothek, Múnich (Cod. Icon. 133). Para la representación de este mapa, véase KUPCᄃKK, Ivan, Munich Portolan Charts: Kunstmann I-XIII and Ten Other Portolan Charts, München, Deutscher Kunstverlag, 2000, pp. 32-33.

52 MORISON, Samuel Eliot, The European Discovery of America. The Southern Voyages A.D. 14921616, New York, Oxford University Press, 1974, p. 306.

${ }_{53}$ Cambridge, Corpus Christi College (Ms. 16, fol. 167r).

${ }^{54}$ En relación con esta imagen, véase LEWIS, Suzanne, The Art of Matthew Paris in the "Chronica majora", Aldershot, Scolar Press; Cambridge, Corpus Christi College, 1987, pp. 285-288.

${ }_{55}$ Para las imágenes del infierno en el arte occidental medieval, véase BASCHET, Jérôme, Les justices de l'au-delà: les représentations de l'enfer en France et en Italie: XIIe-XVe siècle, Rome, École Française de Rome; Paris, diff. De Boccard, 1993. 


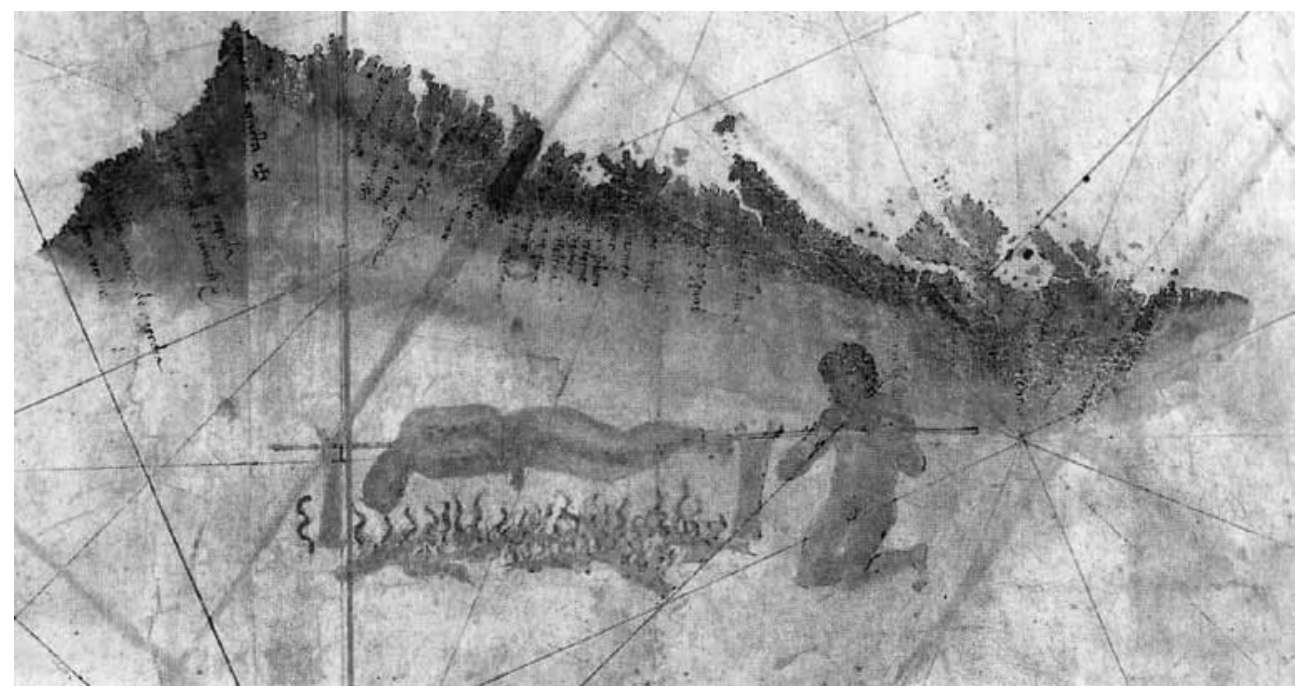

Fig. 2. Mapa de Kunstmann II, ca. 1505, Bayerische Staatsbibliothek, Múnich (Cod. Icon. 133).

de sodomía, sufrían el castigo de ser atravesados por la boca y el ano con un palo, y asados sobre un fuego. Así figura en numerosas imágenes del infierno y Juicios Finales, como la del mosaico del Baptisterio de Florencia (siglo XIII), el fresco de la Capella degli Scrovegni (Padua) de Giotto (ca. 1305) y el del Camposanto de Pisa (finales de la década de 1340?), del que conservamos un grabado realizado en Florencia hacia 1470 que nos permite apreciar el programa original, sin los repintes que el fresco sufrió con posterioridad (el castigo en cuestión figura a los pies de Satán) (fig. 3). Igualmente, vemos reaparecer este tema dentro de la cartografía. En la Carta marina de Martin Waldseemüller $(1516)^{56}$, a diferencia del mapa de Kunstmannn II, el cuerpo de la víctima no se ensarta completamente en un palo, sino que se cocinan miembros amputados. Aunque se omite gráficamente, en el proceso antropofágico interviene el cortar el cuerpo que veíamos con anterioridad representado en los caníbales carniceros. La diferencia con Kunstmann II debe radicar en el hecho de que Waldseemüller estaba siguiendo La Lettera de Vespucio, que Waldseemüller había incluido en su "Quattuor Americi Vespuccij navigations" ("Cuatro viajes de Américo Vespucio") de su Cosmographiae introductio (1507). Asimismo, encontramos reiterados otros elementos típicos de esta escena, como colgar la carne de las ramas, comer restos humanos, transportar nuevas víctimas en este caso, a lomos de un indígena, fiel al texto vespuciano- y vestir con plumas.

56 La única copia existente de este mapa se encuentra en la Jay I. Kislak Collection de la Library of Congress, Washington, DC. Para una reproducción facsimilar, véase FISCHER, Joseph y WIESER, Franz Ritter von, Die älteste Karte mit dem Namen Amerika aus dem Jahre 1507 und die Carta marina aus dem Jahre 1516 des M. Waldseemüller (Ilacomilus), Innsbruck, Wagner'schen Universitäts-Buchhandlung, 1903; Amsterdam, Theatrum orbis terrarum, 1968. 


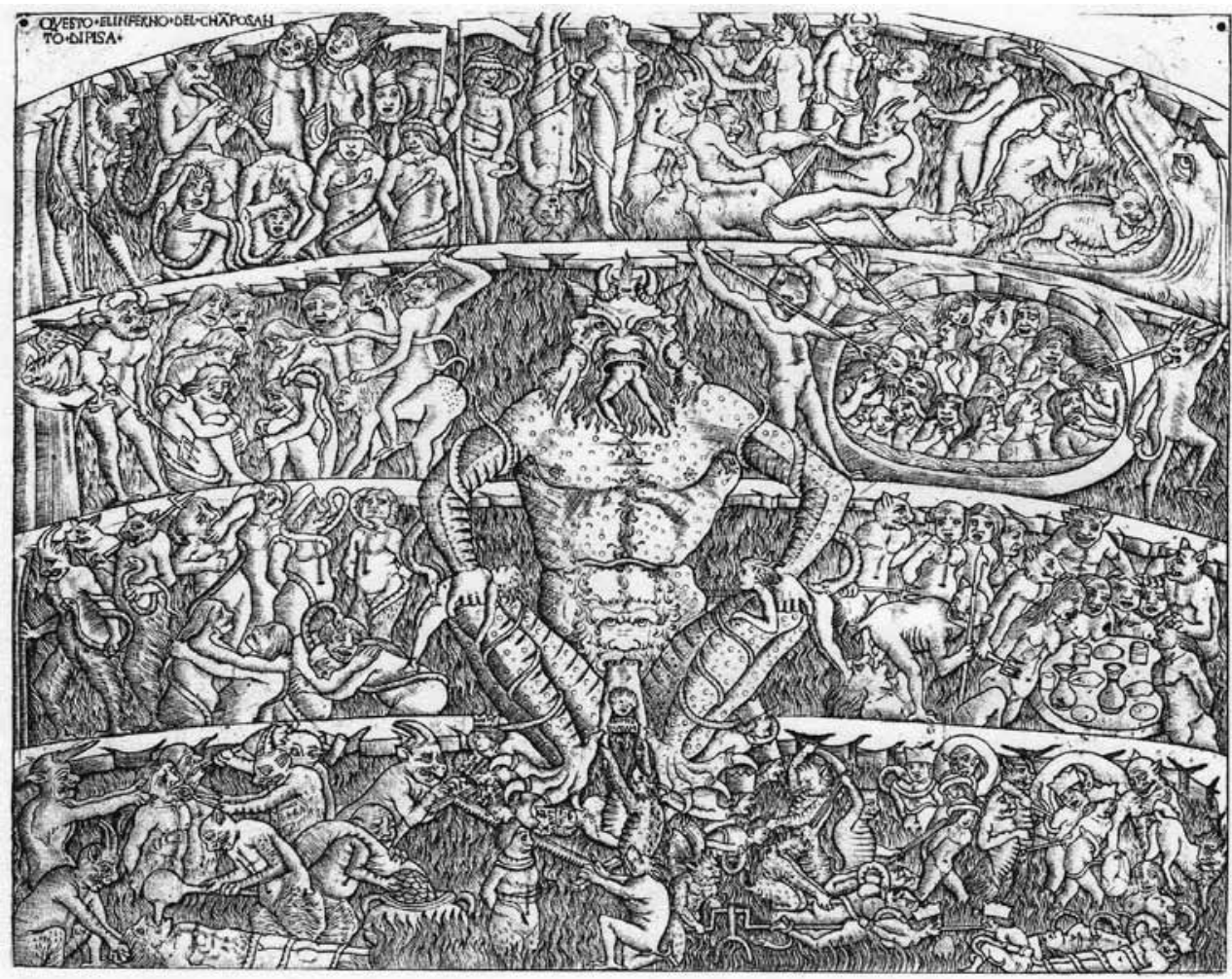

Fig. 3. Grabado del Infierno del Camposanto de Pisa (Florencia, ca. 1470)

El mapa de Sebastian Münster incluido en el Novus Orbis de Johann Huttich y Simon Grynaeus (Basilea, 1532) es también de gran interés para el estudio del canibalismo americano, en concreto la imagen, posiblemente obra de Hans Holbein el Joven, que encontramos en el margen inferior izquierdo del mapa, es decir, próxima a Sudamérica, donde se denunciaban las prácticas antropofágicas (fig. 4). Para su realización, el autor recurrió a numerosos elementos empleados con anterioridad en la iconografía de los caníbales americanos. El personaje de la derecha, que tiene un palo en la mano y conduce un caballo cargado con una víctima atada de pies y manos, es una clara derivación del Uslegung der carta marina (1525) de Lorenz Fries. Igualmente es semejante a este grabado el gesto del carnicero que con el hacha en la mano derecha asegura la carne con la izquierda, mientras que un tercer personaje se encarga de recoger los pedazos que van siendo $\operatorname{cortados}^{57}$. Tanto el hacha como la mesa de carnicero son muy semejantes a

57 CHICANGANA-BAYONA, Yobenj Aucardo, "De Gog y Magog al indio caníbal", conferencia presentada en el Congress of the Latin American Studies Association, celebrado en Rio de Janeiro, Brasil, en junio 11-14, 2009, p. 7, disponible digitalmente online en: http://lasa.international.pitt.edu/members/congress-papers/lasa2009/files/ChicanganaBayonaYobenj.pdf. 


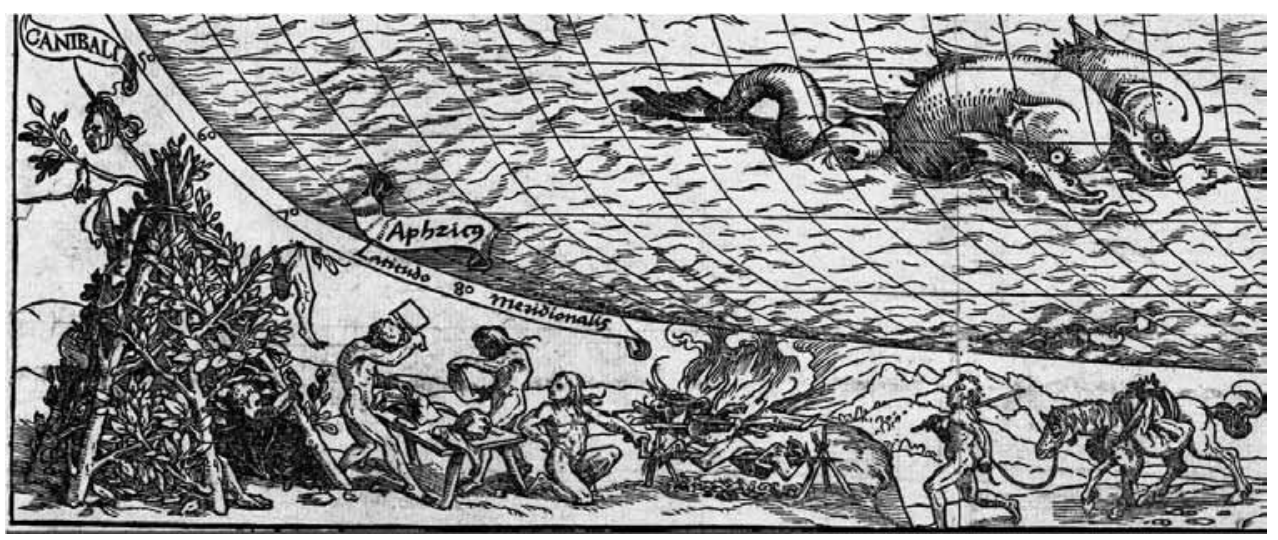

Fig. 4. Detalle de la ilustración realizada por Hans Holbein el Joven en el mapa de Sebastian Münster del Novus Orbis de Johann Huttich y Simon Grynaeus (Basilea, 1532).

las que encontrábamos en anteriores representaciones antropofágicas. También sigue el modelo previo la carne en el asador, que se presenta cortada en trozos atravesados por un palo que un indígena gira sobre el fuego, al igual que en la Carta marina (1516) de Martin Waldseemüller. Dos aspectos son especialmente novedosos en la representación de este tema: la cabaña a la izquierda construida con ramas de la que cuelgan restos humanos, entre ellos una cabeza ${ }^{58}$; y los dos calderos detrás del asador, de uno de los cuales emerge una mano. Este último motivo, y la idea de cocer (y no asar) la carne, los encontramos ilustrados con anterioridad en escenas antropofágicas de los pueblos asiáticos. Por ejemplo, así aparece (incluso el detalle de la mano en el caldero) en un manuscrito de hacia 1410-1412 de Odorico da Pordenone ${ }^{59}$ (fig. 5), en el que se representa a la gente de la llamada isla Dondin, de la que dice este autor que "los hombres tienen la torpe costumbre de comer el padre al hijo y el hijo al padre, diciendo que es mejor comer sus cuerpos que dejar que los gusanos los devoren"60. Tanto la cabaña con los restos humanos colgando, entre ellos una cabeza, como el cocer la carne derivan posiblemente del segundo viaje de Cristóbal Colón al Nuevo Mundo, concretamente de lo que vio la expedición colombina al entrar en las casas de los indígenas, tal como cuenta Pedro Mártir de Anglería en sus Décadas del Nuevo Mundo (Década primera, cap. 2) ${ }^{61}$ :

“... en sus cocinas carnes humanas cocidas con carne de papagayo y de pato, y otras puestas en los asadores para asarlas. Rebuscando lo interior y los escondrijos de las casas, se reconoció que guardaban cada uno con sumo cuidado los huesos de las tibias y los brazos humanos para hacer las puntas de las saetas, pues las fabrican de hueso porque no tie-

58 La cabaña sería adoptada como símbolo del canibalismo de Brasil por Sebastian Münster en sus mapas de 1540,1546 y 1550 .

59 Bibliothèque nationale de France, París, (Ms. Fr. 2810, fol. 107r)-

60 ODORICO, da Pordenone, Relación de Viaje, GUGLIELMI, Nilda (trad.), Buenos Aires, Editorial Biblos, 1987, pp. 69-70.

${ }_{61}$ FERRO, Gaetano (ed.), Columbian iconography, Roma, Istituto Poligrafico e Zecca dello Stato, 1996, p. 90. 


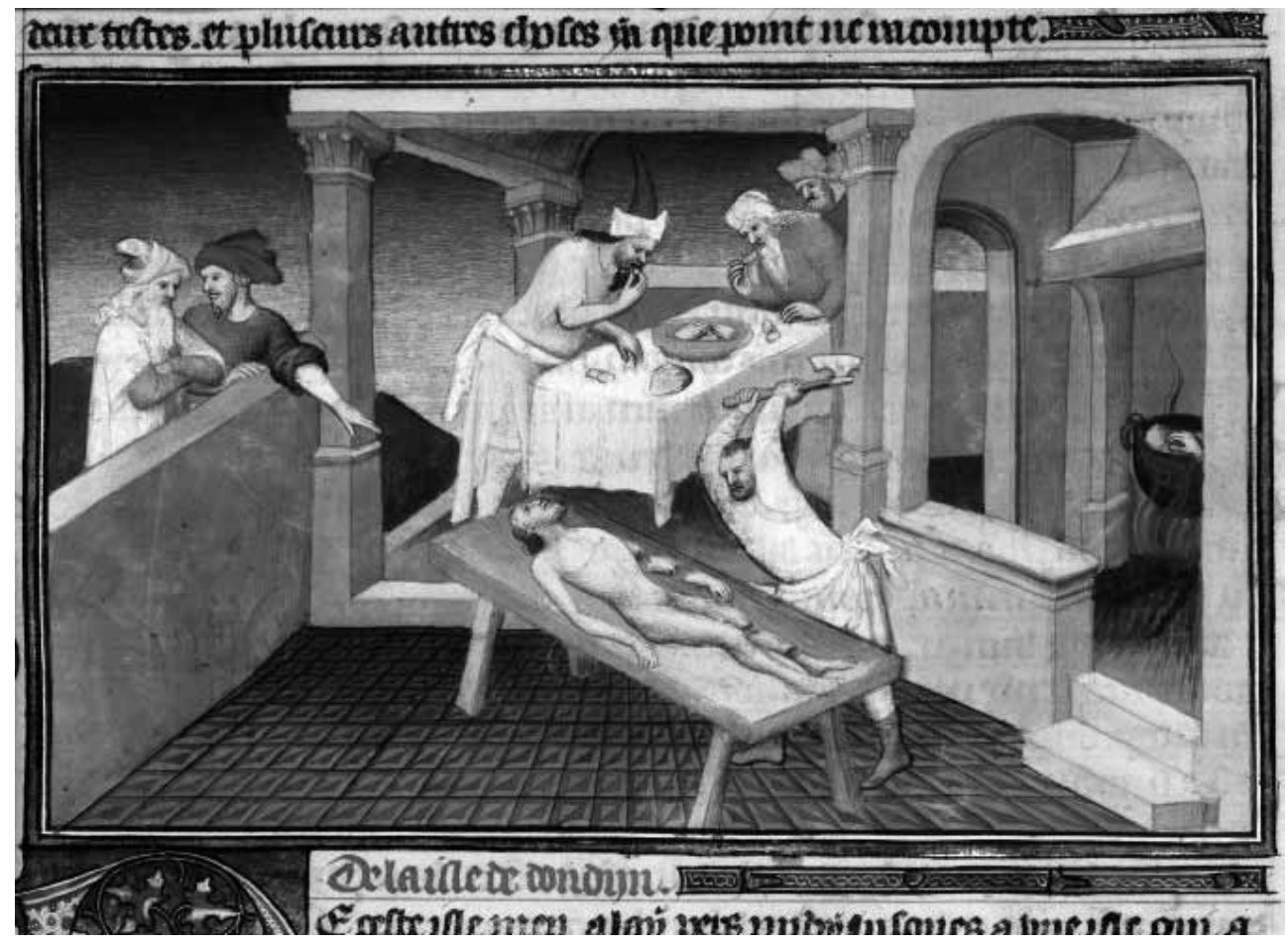

Fig. 5. Odorico da Pordenone, Itinerarium, ca. 1410-12, Bibliothèque nationale de France, París (Ms. fr. 2810, fol. 107r).

nen hierro. Los demás huesos, cuando se han comido la carne, los tiran. Hallaron también la cabeza de un joven recién matado colgada de un palo, con la sangre aún húmeda"62.

Ninguno de los artistas responsables de las imágenes de los indios caníbales americanos vistas hasta ahora estuvo en el Nuevo Mundo, y de ahí que, como hemos insistido, utilizaran recursos iconográficos del arte medieval occidental, no tomados del natural y totalmente anacrónicos. Sin embargo, el panorama artístico del retrato de los indígenas americanos cambió hacia mediados del siglo XVI, con el incremento de las representaciones de los propios viajeros que habían ido allí. Importante al respecto fue la figura del anteriormente mencionado Hans Staden. En su segundo viaje a América, este soldado y marinero alemán fue hecho prisionero por los indios tupinambá con los que convivió algo más de nueve meses, hasta

62 ANGLERÍA, Pedro Mártir de, Décadas del Nuevo Mundo, Madrid, Ediciones Polifemo, 1989, p. 19. El Dr. Diego Álvarez Chanca, médico que acompañó a Cristóbal Colón en su segundo viaje, aportó una información semejante en su carta al Cabildo de Sevilla: “... dizen que la carne del ombre es tan buena que no ay tal cosa en el mundo, y bien pareçe, porque los huesos que en estas casas hallamos, todo lo que se puede roer todo lo tenían roydo, que no avía en ellos sino lo que por su mucha dureza no se podía comer. Allí se halló en una casa, coziendo en una olla, un pescueço de un ombre...”, en MORALES PADRÓN, Francisco, Primeras cartas sobre América (1493-1503), Sevilla, Universidad de Sevilla, 1990, p. 118. 
que un navío francés lo rescató y regresó a Europa en 1555. Dos años más tarde, en 1557, publicó en Marburgo su Verdadera historia... ${ }^{63}$. Esta primera edición se amenizó con xilografías, de las que, aunque Staden no fue el autor material, muy posiblemente supervisó, como se desprende de la existencia de una clara interrelación entre texto e imágenes, de que el propio Hans Staden aparezca retratado constantemente, y de la ausencia de modelos iconográficos previos como los que aquí se ilustran que hubieran servido de base a un artista que no conoció el Nuevo Mundo ${ }^{64}$.

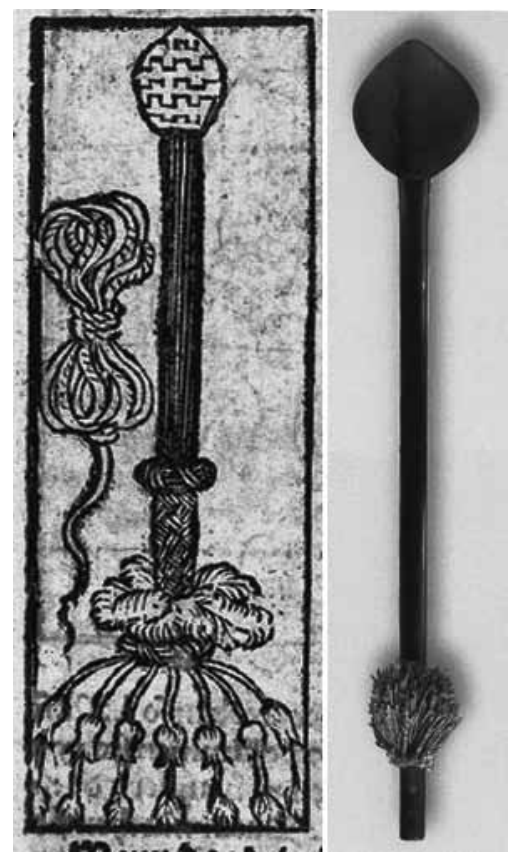

Fig. 6. Iwera Pemme de Hans Staden, Verdadera historia... II, 29 (Marburgo, 1557) y ejemplar brasileño posiblemente Tupí, siglos XVI-XVII, Staatliche Museen zu Berlin, Ethnologisches Museum, Berlín (Inv. Nr. VB 3654).

varas que reposan sobre cuatro horquetas ${ }^{66}$, origen de nuestras modernas barbacoas. ria... sobresalen como fuente documental de la vida y costumbres del pueblo tupinambá, y muy especialmente del ritual antropofágico, a través del cual los indios vengaban la muerte de los que morían a manos de sus enemigos. Durante su cautiverio, Staden presenció la muerte de otros prisioneros que fueron comidos, e incluso él mismo era continuamente amenazado de convertirse en comida. Según se explica en esta obra, la víctima moría de un golpe en la cabeza realizado con un palo llamado Iwera Pemme, ilustrado en las escenas del ritual caníbal y como objeto aislado en el libro II, cap. 29, y de los que se han conservado varios ejemplares (fig. 6). Previamente, este palo y la cabeza del que iba a morir eran decoradas con el mismo motivo. Se le ataba fuertemente con una cuerda a la cintura llamada Mussurana agarrada de los dos extremos, permitiéndole defenderse verbalmente y arrojar pequeñas piedras a las mujeres que le amenazaban con comerle. Una vez muerto, su cuerpo era desmembrado y su carne asada y comida ${ }^{65}$. Es interesante apreciar que el asador en el que la carne es cocinada difiere enormemente de los vistos en anteriores representaciones de los indios caníbales. Se trata del moquém o boucan, una especie de parrilla hecha de

El texto y las imágenes de la Verdadera histo(1)

63 Esta edición está digitalizada online en la "Biblioteca Digital de Obras Raras e Especiais" de la Universidade de São Paulo: http://www.obrasraras.usp.br/.

${ }^{64}$ WHITEHEAD, Neil L. y HARBSMEIER, Michael (2008), op. cit., p. lxxiii; en relación con la veracidad de las experiencias vividas por Hans Staden, véase FORSYTH, Donald W. (1985), op. cit.

65 Véase WHITEHEAD, Neil L. y HARBSMEIER, Michael (2008), op. cit., libro 2, cap. 29, pp. 129-137.

${ }^{66}$ En relación con esta estructura para asar carne, véase CASTILLO MATHIEU, Nicolás del, "Relaciones del Taíno con el Caribe Insular”, en Thesaurus: Boletín del Instituto Caro y Cuervo, vol. 37, n² 2, 1982, pp. 233-254, esp. 246-249. 


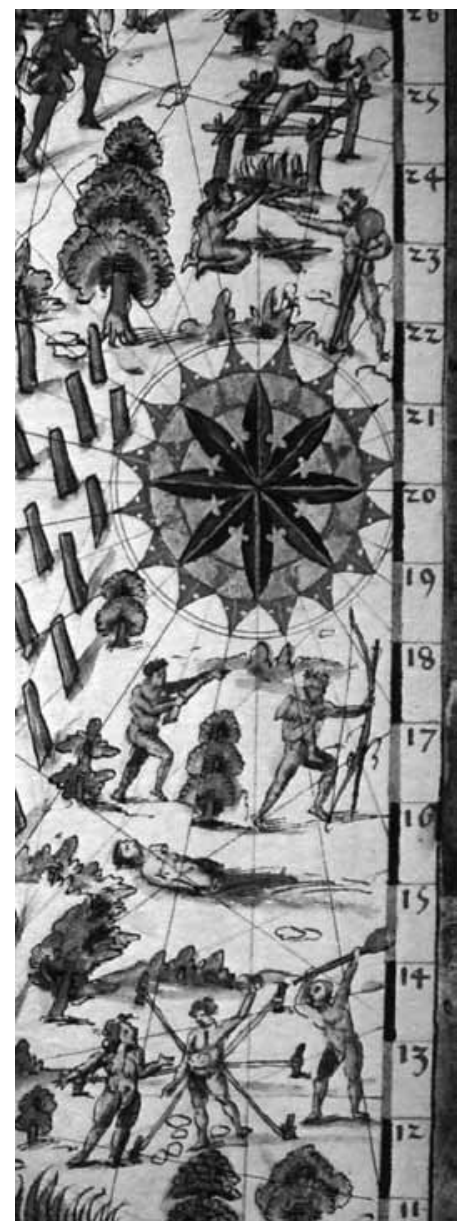

Fig. 7. Detalle del mapa de Brasil de Jean Rotz, Boke of Idrography, 1542, British Library, Londres (Royal Ms. 20.E.IX). bien habia estado en Brasil entre 1556 y 1558, y que veinte annos despues, en 1578 , bién había estado en Brasil entre 1556 y 1558, y que veinte años después, en 1578, publicaba en Francia sus experiencias en la Histoire d'un voyage fait en la terre du Brésil, autrement dit Amérique:

"Durante aproximadamente ese año en el que viví en aquel país, tuve tanto cuidado de observarlos a todos, grandes y pequeños, que incluso ahora me parece que los tengo delante de mis ojos, y para siempre tendré su idea e imagen en mi mente. Pero sus gestos y expresiones son tan completamente distintas de las nuestras que es difícil, debo confe-

67 British Library, Londres (Royal Ms. 20.E.IX). Para una reproducción facsimilar de este mapa, véase WALLIS, Helen (1981), op. cit. 
sar, representarlos bien de forma escrita o en pinturas. Para realmente disfrutar de ello, tendrás que ir y visitarlos en su propio país"68.

Pese a esas dificultades y limitaciones con las que se enfrentaban los artistas occidentales al tratar de captar el Nuevo Mundo, y aunque ninguno de ellos fue ni un Pedro Berruguete, ni un Leonardo da Vinci o un Andrea Mantegna - pintores a los que ansiaba emular Fernández de Oviedo al tratar de documentar esas tierraslas imágenes de aquellos que se atrevieron a mostrar ese Nuevo Mundo es tan solo lo que nos queda a nosotros para disfrutar de él, pues ya tan solo pervive en estos recuerdos, y poco le queda (o hemos dejado) de "nuevo".

68 Traducción de la autora a partir de la inglesa de LÉRY, Jean de, History of a Voyage to the Land of Brazil, Otherwise Called America, WHATLEY, Janet (trad.), Berkeley, University of California Press, 1992, p. 67. 